\title{
Light Cigarette Smoking Increases Risk of All-Cause and Cause-Specific Mortality: Findings from the NHIS Cohort Study
}

\author{
Wen Qin ${ }^{1}$, Costan G. Magnussen ${ }^{2,3}$, Shengxu Li ${ }^{4}$, Lyn M Steffen ${ }^{5}$, Bo Xi ${ }^{6}$ and Min Zhao ${ }^{7, *}$ \\ 1 Shandong University Hospital, Cheeloo College of Medicine, Shandong University, Jinan 250012, China; \\ qinwen@sdu.edu.cn \\ 2 Menzies Institute for Medical Research, University of Tasmania, Hobart 7000, Australia; \\ costan.magnussen@utas.edu.au \\ 3 Research Centre of Applied and Preventive Cardiovascular Medicine, University of Turku, \\ 20520 Turku, Finland \\ 4 Children's Minnesota Research Institute, Children's Hospitals and Clinics, Minneapolis, MN 55404, USA; \\ sli10@tulane.edu \\ 5 Division of Epidemiology and Community Health, School of Public Health, University of Minnesota, \\ Minneapolis, MN 55454, USA; steff025@umn.edu \\ 6 Department of Epidemiology, School of Public Health, Cheeloo College of Medicine, Shandong University, \\ Jinan 250012, China; xibo2007@126.com \\ 7 Department of Nutrition and Food Hygiene, School of Public Health, Cheeloo College of Medicine, \\ Shandong University, Jinan 250012, China \\ * Correspondence: zhaomin1986zm@126.com
}

Received: 16 June 2020; Accepted: 11 July 2020; Published: 15 July 2020

\begin{abstract}
Very few studies have examined the association between light cigarette smoking (i.e., $\leq 5$ cigarettes per day) and mortality. The aim of this study was to examine the association of light cigarette smoking with all-cause and cause-specific mortality among adults in the United States. Data were from 13 waves of the National Health Interview Survey (1997 to 2009) that were linked to the National Death Index records through December 31, 2011. A total of 329,035 participants aged $\geq 18$ years in the United States were included. Deaths were from all cause, cancer, cardiovascular disease (CVD) and respiratory disease and were confirmed by death certification. During a median follow-up of 8.2 years, 34,862 participants died, of which 8415 were from cancer, 9031 from CVD, and 2040 from respiratory disease. Compared with never-smokers, participants who smoked 1-2 (hazard ratios $(\mathrm{HR})=1.94,95 \% \mathrm{CI}=1.73-2.16)$ and $3-5$ cigarettes $(\mathrm{HR}=1.99,1.83-2.17)$ per day were at higher risk of all-cause mortality after adjustment for demographic variables, lifestyle factors and physician-diagnosis of chronic disease. The associations were stronger for respiratory disease-specific mortality, followed by cancer-specific mortality and CVD-specific mortality. For example, the HRs (95\% CIs) of smoking 1-2 cigarettes per day were 9.75 (6.15-15.46), 2.28 (1.84-2.84) and 1.93 (1.58-2.36), respectively, for these three cause-specific mortalities. This study indicates that light cigarette smoking increases risk of all-cause and cause-specific mortality in US adults.
\end{abstract}

Keywords: light smoking; mortality; prospective

\section{Introduction}

Cigarette smoking is a global public health issue [1,2] with about 5 million deaths each year attributable to smoking [3]. In the United States (U.S.), the prevalence of cigarette smoking among adults has declined from $20.9 \%$ in 2005 to $16.8 \%$ in 2014, [4] mainly due to effective tobacco-control 
policies [5]. However, the risk of deaths from cigarette smoking continues to increase among U.S. adults, especially among men [6].

Evidence from the National Health Interview Survey (NHIS) suggests that among daily cigarette smokers, the percentage who smoked less than 10 cigarettes per day increased from $16 \%$ to $27 \%$ from 2005 to 2014 [4]. In addition, it is believed that such a low level of smoking exposure might be safe among $10 \%$ of U.S. adolescents [7]. Nevertheless, light smoking status is common among smokers who are trying to quit and may be maintained for many years during their lifetime [8,9]. In line, previous studies have suggested light smoking isassociated with increased risk of cancer $[10,11]$, coronary heart disease [12] and stroke. However, limited studies have examined the association between light smoking and risk of mortality [13-15]. In addition, participants in most of these studies were either not nationally representative [13-15], restricted to male workers [13] or of older age ( $\geq 59$ years) [14], thus limiting the generalizability of the findings. Importantly, the harmfulness of light smoking has not been given full attention in samples of the general public.

Therefore, we used baseline data from the NHIS collected between 1997 and 2009 linked to data from the National Death Index (NDI) in 2011 to examine the association of cigarette smoking with all-cause and cause-specific mortality among U.S. adults aged $\geq 18$ years.

\section{Materials and Methods}

\subsection{Study Population}

The NHIS is a nationally representative survey of the civilian, noninstitutionalized U.S. population. Detailed information of the NHIS has been described elsewhere [16]. In brief, the NHIS is a cross-sectional survey that has been conducted by the National Center for Health Statistics of the Centers for Disease Control and Prevention since 1957. NHIS uses a stratified, multistage randomized sampling design to collect information using personal household interviews. One sample adult is randomly selected from each household for a detailed interview on health and lifestyle behaviors. NHIS data are de-identified and do not include any protected health information. The data are publicly available and exempt under the ethical board review of the corresponding author's institution.

As the survey questions of the NHIS underwent major revision in 1997, this study is restricted to NHIS data collected from 1997 to 2009 . A total of 366,376 participants aged $\geq 18$ years were included in the preliminary study. Of these, 37,341 were excluded because of missing data on cigarette smoking ( $n=4301)$, missing data on covariates (i.e., demographic variables, lifestyle factors and history of physical-diagnosed diseases; $n=28,859)$ or were pregnant $(n=4181)$, leading to a final sample of 329,035 participants.

\subsection{Mortality Outcomes}

All NHIS participants aged $\geq 18$ years from 1997 to 2009 were linked to the NDI records through December 31, 2011, using a probabilistic matching algorithm to determine mortality status [17]. Validation studies have shown that the information on deaths in the NDI records was accurate and in nearly perfect agreement (98.5\%) [18,19]. Participants not matched with a death record by December 31, 2011 were considered alive. According to the International Classification of Diseases 10th Revision (ICD-10) codes, study outcomes were defined as: (1) all-cause mortality; (2) CVD-specific mortality (codes I00 to I09, I11, I13, I20 to I51and I60 to I69); (3) heart disease-specific mortality (codes I00 to I09, I11, I13 and I20 to I51); (4) cerebrovascular disease-specific mortality (codes I60 to I69); (5) cancer-specific mortality (codes C00 to C97); and (6) chronic lower respiratory diseases (codes J40 to J47).

\subsection{Cigarette Smoking}

We used NHIS participants' responses to two questions to define their smoking status (never, former and current smoking): (1) "Have you smoked at least 100 cigarettes in your ENTIRE LIFE?" (yes vs. no) and (2) "Do you NOW smoke cigarettes?" (yes vs. no). According to the responses to 
these two questions, we categorized participants as never (responded "No" to both questions), former (responded "Yes" to the first question, "No" to the second question) and current smoking (responded "Yes" to the second question). Current smokers were asked "How many cigarettes do you smoke a day?".Similar with previous publications [13-15], we categorized cigarette smoking status into "never", "former", "1-2 cigarettes per day", " $3-5$ cigarettes per day", "6-10 cigarettes per day", "11-20 cigarettes per day", "21-30 cigarettes per day" and ">30 cigarettes per day". In this study, participants who consumed $\leq 5$ cigarettes per day were considered as light cigarette smokers [7].

\subsection{Covariates}

Demographic variables included sex, age, race or ethnicity (White, Black, Hispanic and others), education level (less than high school, high school and beyond high school), marital status (married; divorced, separated or widowed; and never married). Lifestyle variables included body mass index (BMI, weight divided by height squared, $\mathrm{kg} / \mathrm{m} 2)$, physical activity ((PA) whether or not the participants achieved at least $75 \mathrm{~min}$ of vigorous PA or $150 \mathrm{~min}$ of moderate PA in one week according to the Physical Activity Guidelines for Americans [20])) and drinking status (lifetime abstainer, former drinker, current light to moderate drinker (1-7 drinks per week for women and 1-14 drinks per week for men) and current heavy drinker ( $>1$ drinks per day for women and $>2$ drinks per day for men [21,22])). Clinical variables included self-reported physician diagnoses of hypertension, heart disease, stroke, cancer or diabetes.

\subsection{Statistical Analysis}

Differences in baseline participant characteristics between eight categories of cigarette smoking status (never, former smoker, 1-2, 3-5, 6-10, 11-20, 21-30, >30 cigarettes per day) were tested using Chi-square test for categorical variables.

Cox proportional hazards regression model was used to estimate the hazard ratios (HRs) and 95\% confidence intervals (CIs) of cigarette smoking status with all-cause and cause-specific mortality, adjusted for potential covariates. The statistical models were sequentially adjusted for covariates to assess for confounding. Model 1 adjusted for demographic factors (sex, age, race or ethnicity, education level, marital status). Model 2 additionally adjusted for lifestyle factors (BMI, PA, alcohol consumption). Model 3 additionally adjusted for clinical variables (history of physician-diagnosed diseases). Both data pooling and meta-analyses were used to calculate summary HRs and 95\% CIs.

We also examined the association between cigarette smoking status and all-cause mortality by sex, age group and race/ethnicity. Additionally, in sensitivity analyses, (1) participants with a history of physician-diagnosed diseases were excluded because sick individuals were more likely to quit smoking; (2) individuals who died within the first 2 years (i.e., a 2-year lag) were excluded because the deaths were unlikely caused by smoking within short duration; (3) as the missing data accounted for $9.1 \%(33,160 / 366,376)$ in the total population, multiple imputation for variables with missing values were performed.

To quantitatively evaluate the dose-response association of number of cigarettes per day (as a continuous variable) with all-cause and cause-specific mortality, we performed Cox proportional hazards regression models with penalized splines [23], where the reference value assigned was "never smoking", using R software v3.3.3 (R Foundation for Statistical Computing, Vienna, Austria), outputting figures with log HR for all-cause and cause-specific mortality on the $y$-axis and current number of cigarettes per day on the $x$-axis.

Survey weights, strata and cluster in the NHIS design were considered in our data analysis. A two-sided $p<0.05$ was considered statistically significant. All data analyses were performed using SAS version 9.3 (SAS Institute Inc., Cary, North Carolina, USA) and R software v3.3.3 (R Foundation for Statistical Computing, Vienna, Austria). 


\section{Results}

The baseline data included 329,035 U.S. adults. Of these, 72,580 were former cigarette smokers $(22.1 \%)$ and 73,184 were current cigarette smokers $(22.2 \%)$. Table 1 displays baseline characteristics across the eight categories of cigarette smoking status (never, former smoker, 1-2, 3-5, 6-10, 11-20, 21-30 and $>30$ cigarettes per day). We observed significant differences in all examined characteristics across the eight categories of cigarette smoking status (all $p<0.001$; Table 1 ).

During a median (interquartile range) follow-up of 8.2 (5.0-11.5) years, 34,862 participants died, of which 8415 were cancer-specific deaths, 9031 were cardiovascular disease (CVD)-specific deaths and 2040 were respiratory diseases-specific deaths. There was a dose-dependent association of number of cigarettes per day with all-cause mortality as well as with cause-specific mortality (Table 2). Compared with never smokers, those who currently smoked 1-2 cigarettes per day were at high risk of all-cause mortality $(\mathrm{HR}=1.94,95 \% \mathrm{CI}=1.73-2.16)$. The risk was higher among those who smoked 3-5 cigarettes per day $(\mathrm{HR}=1.99,1.83-2.17)$. Similar trends were observed for cause-specific mortality(cancer mortality: 1-2/day: $\mathrm{HR}=2.28(95 \% \mathrm{CI}=1.84-2.84), 3-5 /$ day: $\mathrm{HR}=2.70$ (95\%CI = 2.27-3.21); CVD mortality: 1-2/day: $\mathrm{HR}=1.93$ (95\%CI = 1.58-2.36), 3-5/day: HR = 1.96 $(95 \% \mathrm{CI}=1.63-2.35)$; respiratory disease mortality: $1-2 /$ day: $\mathrm{HR}=9.75(95 \% \mathrm{CI}=6.15-15.46), 3-5 /$ day: $\mathrm{HR}=11.71(95 \% \mathrm{CI}=8.84-15.52))$. (Table 2$)$.

In meta-analysis of the 13 NHIS survey years (Table S1), results were similar with those from pooled analyses. In sensitivity analyses that excluded participants who died within the first 2 years of follow-up or after exclusion of participants who self-reported physician diagnosis of chronic diseases or that based on imputed data, the results were similar to those shown for the pooled analyses (Tables S2-S4). In the subgroup analyses, the associations tended to be stronger among women, those of older age, and among whites (Table S5).

Cox models with penalized splines showed that there were curvilinear dose-response associations of number of cigarettes per day (as a continuous variable) with risk of all-cause mortality (Figure S1-A), cancer-specific mortality (Figure S1-B), CVD-specific mortality (Figure S1-C) and respiratory disease-specific mortality (Figure S1-D), with all $p<0.001$ for the nonlinear tests. Compared with never smokers, those who reported any number of cigarettes per day had higher risk of all-cause and cause-specific mortality. 
Table 1. Baseline Characteristics according to cigarette smoking status, National Health Interview Survey (NHIS), $1997-2009$.

\begin{tabular}{|c|c|c|c|c|c|c|c|c|c|}
\hline & \multicolumn{8}{|c|}{ Cigarette Smoking Status } & \multirow{3}{*}{$p$ Value } \\
\hline & \multirow{2}{*}{ Never } & \multirow{2}{*}{ Former Smoker } & \multicolumn{6}{|c|}{ Current Smoker, Cigarettes Per Day } & \\
\hline & & & $1-2$ & $3-5$ & $6-10$ & $11-20$ & $21-30$ & $>30$ & \\
\hline$N$ & 183,269 & 72,580 & 6933 & 10,288 & 18,266 & 27,997 & 5573 & 4129 & \\
\hline Age, yrs, \% & & & & & & & & & $<0.0001$ \\
\hline $18-39$ & 46.7 & 20.8 & 59.6 & 55.8 & 51.7 & 44.2 & 36.2 & 26.1 & \\
\hline $40-59$ & 33.9 & 39.8 & 30.4 & 33.3 & 36.8 & 42.8 & 50.3 & 58.8 & \\
\hline$\geq 60$ & 19.5 & 39.4 & 10.0 & 10.9 & 11.4 & 13.0 & 13.4 & 15.1 & \\
\hline Sex, $\%$ & & & & & & & & & $<0.0001$ \\
\hline Men & 43.8 & 57.3 & 56.6 & 50.4 & 46.5 & 55.2 & 64.6 & 71.5 & \\
\hline Women & 56.2 & 42.7 & 43.4 & 49.6 & 53.5 & 44.8 & 35.4 & 28.5 & \\
\hline Race/ethnicity, \% & & & & & & & & & $<0.0001$ \\
\hline White & 66.6 & 82.1 & 57.6 & 58.6 & 69.3 & 84.3 & 91.9 & 92.0 & \\
\hline Black & 13.0 & 7.3 & 13.6 & 18.6 & 16.9 & 8.4 & 4.1 & 4.0 & \\
\hline Hispanic & 14.5 & 7.7 & 23.5 & 17.5 & 9.3 & 4.6 & 2.4 & 2.3 & \\
\hline Other & 5.8 & 2.9 & 5.2 & 5.3 & 4.4 & 2.6 & 1.6 & 1.7 & \\
\hline Education, \% & & & & & & & & & $<0.0001$ \\
\hline$<$ High school & 15.2 & 16.2 & 20.0 & 20.0 & 21.0 & 21.1 & 23.5 & 30.1 & \\
\hline High school & 25.9 & 29.5 & 27.8 & 30.3 & 35.7 & 40.5 & 41.5 & 39.9 & \\
\hline >High school & 58.8 & 54.3 & 52.2 & 49.7 & 43.3 & 38.4 & 35.1 & 30.0 & \\
\hline Marital status, $\%$ & & & & & & & & & $<0.0001$ \\
\hline Married & 57.6 & 67.0 & 45.9 & 42.0 & 43.8 & 48.9 & 51.7 & 55.4 & \\
\hline Divorced/separated/widowed & 14.9 & 19.8 & 14.7 & 17.7 & 19.4 & 21.2 & 22.6 & 24.4 & \\
\hline Never married & 27.5 & 13.1 & 39.4 & 40.3 & 36.9 & 29.9 & 25.7 & 20.2 & \\
\hline BMI category, $\mathrm{kg} / \mathrm{m}^{2}, \%$ & & & & & & & & & $<0.0001$ \\
\hline$<18.5$ & 1.9 & 1.3 & 2.1 & 2.9 & 3.4 & 2.8 & 2.2 & 2.5 & \\
\hline $18.5-24.9$ & 39.7 & 32.2 & 42.1 & 43.6 & 43.8 & 43.2 & 39.0 & 34.8 & \\
\hline $25.0-29.9$ & 34.6 & 39.0 & 34.2 & 33.8 & 31.8 & 33.4 & 35.7 & 35.2 & \\
\hline$\geq 30.0$ & 23.7 & 27.5 & 21.6 & 19.7 & 21.0 & 20.7 & 23.1 & 27.6 & \\
\hline Physical activity (meeting recommendation), \% & & & & & & & & & $<0.0001$ \\
\hline No & 59.2 & 58.3 & 56.1 & 57.4 & 64.1 & 66.6 & 70.3 & 75.0 & \\
\hline Yes & 40.8 & 41.7 & 43.9 & 42.6 & 35.9 & 33.4 & 29.7 & 25.0 & \\
\hline
\end{tabular}


Table 1. Cont

\begin{tabular}{|c|c|c|c|c|c|c|c|c|c|}
\hline & \multicolumn{8}{|c|}{ Cigarette Smoking Status } & \multirow{3}{*}{$p$ Value } \\
\hline & \multirow{2}{*}{ Never } & \multirow{2}{*}{ Former Smoker } & \multicolumn{6}{|c|}{ Current Smoker, Cigarettes Per Day } & \\
\hline & & & $1-2$ & $3-5$ & $6-10$ & $11-20$ & $21-30$ & $>30$ & \\
\hline Drinking, $\%$ & & & & & & & & & \multirow[t]{5}{*}{$<0.0001$} \\
\hline Lifetime abstainer & 32.5 & 8.9 & 10.3 & 10.6 & 10.6 & 9.4 & 7.8 & 9.2 & \\
\hline Former drinker & 11.3 & 23.3 & 9.0 & 11.3 & 14.1 & 16.3 & 19.6 & 22.5 & \\
\hline Light to moderate & 53.7 & 62.3 & 72.4 & 68.0 & 65.9 & 63.0 & 55.8 & 50.2 & \\
\hline Heavy & 2.5 & 5.5 & 8.3 & 10.1 & 9.4 & 11.3 & 16.8 & 18.1 & \\
\hline \multicolumn{10}{|c|}{ Physician-diagnosed disease, $\%$} \\
\hline Hypertension & 23.0 & 36.4 & 18.4 & 18.8 & 20.5 & 21.8 & 25.8 & 31.3 & $<0.0001$ \\
\hline Heart disease & 9.1 & 19.6 & 8.5 & 8.1 & 9.5 & 10.6 & 11.8 & 15.5 & $<0.0001$ \\
\hline Stroke & 1.8 & 4.3 & 1.6 & 1.9 & 2.0 & 2.3 & 2.7 & 3.5 & $<0.0001$ \\
\hline Cancer & 5.7 & 12.3 & 3.9 & 4.3 & 5.2 & 6.4 & 7.5 & 8.0 & $<0.0001$ \\
\hline Diabetes & 6.0 & 11.0 & 5.1 & 4.5 & 5.0 & 5.0 & 6.3 & 9.4 & $<0.0001$ \\
\hline
\end{tabular}


Table 2. Association of cigarette smoking status with risk of all-cause and cause-specific mortality.

\begin{tabular}{|c|c|c|c|c|c|c|c|c|}
\hline & \multicolumn{8}{|c|}{ Cigarette Smoking Status, Hazard Ratios (HRs), (95\% CIs) } \\
\hline & \multirow{2}{*}{ Never } & \multirow{2}{*}{ Former Smoker } & \multicolumn{6}{|c|}{ Current Smoker, Cigarettes Per Day } \\
\hline & & & $1-2$ & $3-5$ & 6-10 & 11-20 & $21-30$ & $>30$ \\
\hline \multicolumn{8}{|l|}{ All causes } & 4129 \\
\hline No. of deaths & 14,646 & 12,440 & 513 & 827 & 1626 & 3171 & 793 & 846 \\
\hline Model 1 & 1 & $1.36(1.32-1.40)$ & $1.88(1.68-2.10)$ & $1.96(1.79-2.13)$ & $2.04(1.91-2.16)$ & $2.25(2.14-2.36)$ & $2.70(2.48-2.94)$ & $3.49(3.21-3.80)$ \\
\hline Model 2 & 1 & $1.45(1.40-1.49)$ & $1.96(1.76-2.19)$ & $2.04(1.87-2.22)$ & $2.09(1.96-2.22)$ & $2.30(2.19-2.42)$ & $2.77(2.54-3.02)$ & $3.54(3.25-3.85)$ \\
\hline Model 3 & 1 & $1.34(1.30-1.38)$ & $1.94(1.73-2.16)$ & $1.99(1.83-2.17)$ & $2.05(1.93-2.18)$ & $2.22(2.11-2.34)$ & $2.63(2.40-2.88)$ & $3.34(3.06-3.64)$ \\
\hline \multicolumn{9}{|l|}{ Cancer } \\
\hline No. of deaths & 2898 & 3159 & 121 & 217 & 452 & 1020 & 262 & 286 \\
\hline Model 1 & 1 & $1.73(1.64-1.84)$ & $2.28(1.82-2.84)$ & $2.75(2.32-3.25)$ & $2.59(2.31-2.91)$ & $3.50(3.22-3.81)$ & $4.38(3.79-5.05)$ & $5.68(4.91-6.58)$ \\
\hline Model 2 & 1 & $1.80(1.69-1.91)$ & $2.29(1.83-2.85)$ & $2.74(2.31-3.25)$ & $2.54(2.27-2.86)$ & $3.43(3.14-3.75)$ & $4.31(3.73-4.99)$ & $5.54(4.79-6.42)$ \\
\hline Model 3 & 1 & $1.67(1.56-1.77)$ & $2.28(1.84-2.84)$ & $2.70(2.27-3.21)$ & $2.49(2.22-2.80)$ & $3.29(3.01-3.60)$ & $4.02(3.47-4.66)$ & $5.26(4.54-6.10)$ \\
\hline \multicolumn{9}{|l|}{ CVD } \\
\hline No. of deaths & 4120 & 3183 & 121 & 176 & 387 & 683 & 186 & 175 \\
\hline Model 1 & 1 & $1.23(1.16-1.30)$ & $1.88(1.53-2.30)$ & $1.93(1.60-2.31)$ & $2.33(2.02-2.68)$ & $2.39(2.16-2.64)$ & $3.16(2.65-3.75)$ & $3.59(3.01-4.29)$ \\
\hline Model 2 & 1 & $1.34(1.27-1.43)$ & $2.01(1.64-2.46)$ & $2.05(1.70-2.46)$ & $2.47(2.14-2.85)$ & $2.52(2.27-2.78)$ & $3.35(2.81-3.99)$ & $3.73(3.11-4.48)$ \\
\hline Model 3 & 1 & $1.21(1.14-1.28)$ & $1.93(1.58-2.36)$ & $1.96(1.63-2.35)$ & $2.40(2.07-2.77)$ & $2.36(2.11-2.64)$ & $3.09(2.56-3.72)$ & $3.46(2.89-4.15)$ \\
\hline \multicolumn{9}{|l|}{ Heart disease } \\
\hline No. of deaths & 3053 & 2543 & 91 & 136 & 307 & 573 & 159 & 154 \\
\hline Model 1 & 1 & $1.29(1.21-1.37)$ & $1.76(1.38-2.24)$ & $1.86(1.53-2.26)$ & $2.47(2.10-2.91)$ & $2.53(2.26-2.83)$ & $3.53(2.91-4.27)$ & $3.94(3.26-4.75)$ \\
\hline Model 2 & 1 & $1.40(1.32-1.50)$ & $1.89(1.48-2.40)$ & $1.99(1.63-2.42)$ & $2.65(2.24-3.14)$ & $2.69(2.40-3.02)$ & $3.76(3.10-4.56)$ & $4.11(3.39-4.98)$ \\
\hline Model 3 & 1 & $1.25(1.17-1.33)$ & $1.83(1.43-2.33)$ & $1.90(1.56-2.31)$ & $2.56(2.16-3.04)$ & $2.51(2.22-2.84)$ & $3.47(2.83-4.25)$ & $3.78(3.12-4.58)$ \\
\hline \multicolumn{9}{|c|}{ Cerebrovascular disease } \\
\hline No. of deaths & 1067 & 640 & 30 & 40 & 80 & 110 & 27 & 21 \\
\hline Model 1 & 1 & $1.07(0.95-1.20)$ & $2.43(1.57-3.77)$ & $2.26(1.51-3.39)$ & $2.02(1.57-2.59)$ & $1.94(1.56-2.42)$ & $1.92(1.26-2.94)$ & $2.39(1.48-3.88)$ \\
\hline Model 2 & 1 & $1.19(1.05-1.35)$ & $2.57(1.66-3.99)$ & $2.32(1.55-3.49)$ & $2.04(1.59-2.63)$ & $1.98(1.59-2.46)$ & $1.99(1.30-3.04)$ & $2.44(1.50-3.97)$ \\
\hline Model 3 & 1 & $1.10(0.97-1.24)$ & $2.49(1.64-3.80)$ & $2.23(1.49-3.33)$ & $1.99(1.54-2.57)$ & $1.83(1.46-2.30)$ & $1.75(1.13-2.69)$ & $2.35(1.44-3.81)$ \\
\hline \multicolumn{9}{|c|}{ Respiratory diseases } \\
\hline No. of deaths & 294 & 1020 & 32 & 77 & 163 & 298 & 70 & 86 \\
\hline Model 1 & 1 & $6.66(5.66-7.84)$ & $9.91(6.17-15.93)$ & $12.66(9.56-16.77)$ & $15.32(12.22-19.22)$ & $16.57(13.53-20.29)$ & 21.10(15.33-29.04) & $35.11(26.10-47.23)$ \\
\hline Model 2 & 1 & $7.55(6.39-8.93)$ & $9.97(6.26-15.89)$ & $12.17(9.19-16.12)$ & $13.92(11.09-17.48)$ & $15.26(12.49-18.64)$ & $20.05(14.56-27.61)$ & $32.38(24.14-43.42)$ \\
\hline Model 3 & 1 & $6.96(5.88-8.23)$ & $9.75(6.15-15.46)$ & $11.71(8.84-15.52)$ & $13.79(10.96-17.35)$ & $14.53(11.86-17.79)$ & $18.52(13.44-25.52)$ & $30.52(22.63-41.15)$ \\
\hline
\end{tabular}

Model 3: Model 2 plus additionally adjusted for physician-diagnosed diseases (hypertension, heart disease, stroke, cancer and diabetes). 


\section{Discussion}

To our knowledge, this is the first nationally representative and large-scale study examining the association of light cigarette smoking (i.e., $\leq 5$ cigarettes per day)with risk of all-cause and cause-specific mortality among U.S. adults. Our findings highlight that there is no safe threshold for cigarette smoking, and effective smoking control programs should be conducted to prevent smoking in the general population to reduce risk of mortality.

\section{Comparison with Previous Studies}

Many prospective studies have examined the association of light cigarette smoking with risk of cancer [10,11] and CVD [12]. The NIH-AARP Diet and Health Study of 238,525 healthy adults aged $\geq 59$ years found that compared with never smokers, smokers who smoked $<1$ and 1-10 cigarettes per day were at higher risk of incident cancer [11]. A recent meta-analysis of 141 cohort studies found that smoking just one cigarette per day increased risk of coronary heart disease and stroke [12]. However, to our knowledge, only few studies have assessed the association of light smoking with risk of mortality [13-15] and the findings were inconsistent. In 2002, the Copenhagen City Heart Study of 12,149 adults aged $\geq 30$ years showed that smoking less than $3 \mathrm{~g}$ of tobacco per day was not associated with a significantly increased risk of myocardial infarction and all-cause mortality (women: $\mathrm{HR}=1.24$, $95 \% \mathrm{CI}=0.79-1.94$; men: $\mathrm{HR}=1.32,95 \% \mathrm{CI}=0.49-3.56$ ). Increased risk seemed to commence from $3 \mathrm{~g}$ of tobacco per day [15]. Another prospective study of 25,464 Japanese workers aged 20-61 years showed there was no significant association between a smoking level of 1-10 cigarettes per day and all-cause mortality $(\mathrm{HR}=1.51,95 \% \mathrm{CI}=0.73-2.94)$ [13]. The nonsignificant associations in the above two studies could be due to insufficient statistical power in the light smoking groups. Consistent with our findings, the NIH-AARP Diet and Health Study of 290,215 healthy adults aged $\geq 59$ years found occasional smokers (participants who smoked less than 1 cigarette per day) were at higher risk of all-cause mortality $(\mathrm{HR}=1.64,95 \% \mathrm{CI}=1.07-2.51)$, as well as several cause-specific mortality outcomes (e.g., lung cancer-specific mortality and CVD-specific mortality) [14]. In addition, we found that the younger participants (18-39 years of age) are more likely to be light cigarette smokers than those in other age categories. This suggests that the younger people are in a more unstable smoking pattern and possibly on a trajectory where an increase in number of cigarettes is more common than the older and more established smokers.

\section{Public Health Implications}

Our findings have several important public health implications. First, our results are consistent with the 2008 Public-Health-Service-sponsored Clinical Practice Guidelines and the 2010 Surgeon General's Report that no risk-free level of cigarette smoking exists, and even 1-2 cigarettes per day is harmful for health. Thus, it is important that never smokers (especially for young people) should not try to smoke cigarettes, and current cigarette smokers should stop smoking to obtain substantial health benefits. Second, the government should disseminate the dangers of light cigarette smoking via social media. The government should also provide smoking cessation services for current smokers to help them stop smoking. In addition, health professionals and primary care physicians also should inform their patients either not to smoke any dose of cigarettes or to completely stop smoking.

\section{Study Strengths and Limitations}

The main strengths of our study included the very large sample size, relatively longer duration of follow-up, adjustment for potential confounding factors, the use of several sensitivity analyses to test the stability of our findings and the generalizability of our results to the US adults. However, several limitations should be considered. First, information on cigarette smoking was self-reported which might be subject to recall bias. However, validation studies suggest that self-report data are strongly correlated with measured levels of cotinine in blood or urine [24]. Second, cigarette smoking status 
was only available at baseline, and the change in cigarette smoking status among participants during follow-up might have influenced the findings.

\section{Conclusions}

Our data suggest that light cigarette smoking is associated with higher risk of all-cause and cause-specific mortality compared with never smokers. These data indicate that there is no safe level of cigarette smoking. Our data reinforce the importance of quitting programs aimed at current cigarette smokers across the life-course.

Supplementary Materials: The following are available online at http://www.mdpi.com/1660-4601/17/14/5122/s1, Figure S1: Dose-response associations of cigarette smoking with (A) all-cause, (B) cancer-specific mortality, (C) CVD-specific mortality, and (D) respiratory disease-specific mortality in U.S. adults; Table S1: Meta-analyses of cigarette smoking status with risk of all-cause mortality according to baseline survey year; Table S2: Cigarette smoking status and risk of all-cause and cause-specific mortality (Exclusion of participants who died within the first 2 years of follow up);Table S3: Cigarette smoking status and risk of all-cause and cause-specific mortality (Exclusion of participants who had history of physician-diagnosed diseases); Table S4: Cigarette smoking status and risk of all-cause and cause-specific mortality (using imputed data); Table S5: Cigarette smoking status and risk of all-cause mortality by sex, age group and race/ethnicity.

Author Contributions: M.Z. conceived and designed the study. W.Q. drafted the manuscript. M.Z. collated and analyzed the data. C.G.M. obtained funding. All authors critically revised the manuscript for important intellectual content. M.Z. is responsible for study supervision and is the study guarantor. M.Z. had full access to all of the data in the study and can take responsibility for the integrity of the data and the accuracy of the data analysis. All authors have read and agreed to the published version of the manuscript.

Funding: Costan G. Magnussen is supported by a National Heart Foundation of Australia Future Leader Fellowship (100849). The sponsors had no role in the study design, survey process, data analysis or manuscript preparation.

Acknowledgments: The authors thank the National Center for Health Statistics of the Centers for Disease Control and Prevention for sharing the NHIS data.

Conflicts of Interest: The authors declare no conflict of interest.

\section{References}

1. Giovino, G.A.; Mirza, S.A.; Samet, J.M.; Gupta, P.C.; Jarvis, M.J.; Bhala, N.; Peto, R.; Zatonski, W.; Hsia, J.; Morton, J.; et al. Tobacco use in 3 billion individuals from 16 countries: An analysis of nationally representative cross-sectional household surveys. Lancet 2012, 380, 668-679. [CrossRef]

2. Ng, M.; Freeman, M.K.; Fleming, T.D.; Robinson, M.; Dwyer-Lindgren, L.; Thomson, B.; Wollum, A.; Sanman, E.; Wulf, S.; Lopez, A.D.; et al. Smoking Prevalence and Cigarette Consumption in 187 Countries, 1980-2012. JAMA 2014, 311, 183-192. [CrossRef] [PubMed]

3. World Health Organization. WHO Grobal Report: Mortality Attributable to Tobacco; World Health Organization: Geneva, Switzerland, 2012.

4. Jamal, A.; Homa, D.M.; O'Connor, E.; Babb, S.D.; Caraballo, R.S.; Singh, T.; Hu, S.S.; King, B.A. Current cigarette smoking Among Adults-United States, 2005-2014. MMWR Morb. Mortal. Wkly. Rep. 2015, 64, 1233-1240. [CrossRef] [PubMed]

5. Holford, T.R.; Meza, R.; Warner, K.E.; Meernik, C.; Jeon, J.; Moolgavkar, S.H.; Levy, D.T. Tobacco Control and the Reduction in Smoking-Related Premature Deaths in the United States, 1964-2012. JAMA 2014, 311, 164-171. [CrossRef] [PubMed]

6. Thun, M.J.; Carter, B.D.; Feskanich, D.; Freedman, N.D.; Prentice, R.; Lopez, A.D.; Hartge, P.; Gapstur, S.M. 50-Year Trends in Smoking-Related Mortality in the United States. N. Engl. J. Med. 2013, 368, 351-364. [CrossRef] [PubMed]

7. Amrock, S.M.; Weitzman, M. Adolescents' Perceptions of Light and Intermittent Smoking in the United States. Pediatrics 2015, 135, 246-254. [CrossRef] [PubMed]

8. Wortley, P.M.; Husten, C.G.; Trosclair, A.; Chrismon, J.; Pederson, L.L. Nondaily smokers: A descriptive analysis. Nicotine Tob. Res. 2003, 5, 755-759. [CrossRef] [PubMed]

9. Schane, R.E.; Glantz, S.A.; Ling, P.M. Nondaily and Social Smoking an Increasingly Prevalent Pattern. Arch. Intern. Med. 2009, 169, 1742-1744. [CrossRef] [PubMed] 
10. Berthiller, J.; Straif, K.; Agudo, A.; Ahrens, W.; dos Santos, A.B.; Boccia, S.; Cadoni, G.; Canova, C.; Castellsague, $X . ;$ Chen, C.; et al. Low frequency of cigarette smoking and the risk of head and neck cancer in the INHANCE consortium pooled analysis. Int. J. Epidemiol. 2016, 45, 835-845. [CrossRef] [PubMed]

11. Inoue-Choi, M.; Hartge, P.; Liao, L.M.; Caporaso, N.; Freedman, N.D. Association between long-term low-intensity cigarette smoking and incidence of smoking-related cancer in the national institutes of health-AARP cohort. Int. J. Cancer 2018, 142, 271-280. [CrossRef] [PubMed]

12. Hackshaw, A.; Morris, J.K.; Boniface, S.; Tang, J.L.; Milenkovic, D. Low cigarette consumption and risk of coronary heart disease and stroke: Meta-analysis of 141 cohort studies in 55 study reports. BMJ 2018, 361, j5855. [CrossRef] [PubMed]

13. Kondo, T.; Osugi, S.; Shimokata, K.; Honjo, H.; Morita, Y.; Maeda, K.; Yamashita, K.; Muramatsu, T.; Shintani, S.; Matsushita, K.; et al. Smoking and Smoking Cessation in Relation to All-Cause Mortality and Cardiovascular Events in 25,464 Healthy Male Japanese Workers. Circul. J. 2011, 75, 2885-2892. [CrossRef] [PubMed]

14. Inoue-Choi, M.; Liao, L.M.; Reyes-Guzman, C.; Hartge, P.; Caporaso, N.; Freedman, N.D. Association of Long-term, Low-Intensity Smoking With All-Cause and Cause-Specific Mortality in the National Institutes of Health-AARP Diet and Health Study. JAMA Intern. Med. 2017, 177, 87-95. [CrossRef] [PubMed]

15. Prescott, E.; Scharling, H.; Osler, M.; Schnohr, P. Importance of light smoking and inhalation habits on risk of myocardial infarction and all cause mortality. A 22 year follow up of 12149 men and women in The Copenhagen City Heart Study. J. Epidemiol. Community Health 2002, 56, 702-706. [CrossRef] [PubMed]

16. National Center for Health Statistics. National Health Interview Survey. Available online: https://www.cdc. gov/nchs/nhis/index.htm (accessed on 16 June 2020).

17. National Center for Health Statistics of Centers for Disease Control and Prevention. NCHS 2011 Linked Mortality Files Matching Methodology. Available online: http://www.cdc.gov/nchs/data_access/data_linkage/ mortality/linkage_methods_analytical_support/2011_linked_mortality_file_matching_methodology.pdf (accessed on 16 June 2020).

18. National Center for Health Statistics. NHANES I Epidemiologic Follow-up Survey (NHEFS)—Calibration Sample for NDI Matching Methodology. Available online: http://www.cdc.gov/nchs/data/datalinkage/mort_ calibration_study.pdf (accessed on 16 June 2020).

19. Lochner, K.; Hummer, R.A.; Bartee, S.; Wheatcroft, G.; Cox, C. The public-use National Health Interview Survey linked mortality files: Methods of reidentification risk avoidance and comparative analysis. Am. J. Epidemiol. 2008, 168, 336-344. [CrossRef] [PubMed]

20. Physical Activity Guidelines Advisory Committee. Physical Activity Guidelines Advisory Committee Report US; Physical Activity Guidelines Advisory Committee: Washington, DC, USA, 2008.

21. U.S. Department of Health and Human Services and U.S. Department of Agriculture. 2015-2020 Dietary Guidelines for Americans, 8th ed. Available online: https:/health.gov/dietaryguidelines/2015/guidelines/ (accessed on 16 June 2020).

22. Xi, B.; Veeranki, S.P.; Zhao, M.; Ma, C.; Yan, Y.; Mi, J. Relationship of Alcohol Consumption to All-Cause, Cardiovascular, and Cancer-Related Mortality in U.S. Adults. J. Am. Coll. Cardiol. 2017, 70, 913-922. [CrossRef] [PubMed]

23. Eisen, E.A.; Agalliu, I.; Thurston, S.W.; Coull, B.A.; Checkoway, H. Smoothing in occupational cohort studies: An illustration based on penalised splines. Occup. Environ. Med. 2004, 61, 854-860. [CrossRef] [PubMed]

24. Shiffman, S.; Dunbar, M.S.; Benowitz, N.L. A Comparison of Nicotine Biomarkers and Smoking Patterns in Daily and Nondaily Smokers. Cancer Epidemiol. Biomark. Prev. 2014, 23, 1264-1272. [CrossRef] [PubMed]

(C) 2020 by the authors. Licensee MDPI, Basel, Switzerland. This article is an open access article distributed under the terms and conditions of the Creative Commons Attribution (CC BY) license (http://creativecommons.org/licenses/by/4.0/). 